\title{
Axial Heterogeneity of Intracellular pH in Rat Proximal Convoluted Tubule
}

\author{
Enrique Pastoriza-Munoz, Robin M. Harrington, and Mark L. Graber \\ Veterans Administration Medical Center, Northport, New York 11768; and Department of Medicine, \\ State University of New York at Stony Brook, New York 11794
}

\begin{abstract}
In the proximal convoluted tubule (PT), the $\mathrm{HCO}_{3}^{-}$reabsorptive rate is higher in early (EPS) compared with late proximal segments (LPS). To examine the mechanism of this $\mathrm{HCO}_{3}^{-}$reabsorption profile, intracellular $\mathrm{pH}\left(\mathrm{pH}_{i}\right)$ was measured along the superficial PT of the rat under free-flow and stationary microperfusion using the $\mathrm{pH}$-sensitive fluorescence of 4-methylumbelliferone ( $4 \mathrm{MU})$. With $4 \mathrm{MU}$ superfusion, $\mathrm{pH}_{4}$ was found to decline along the PT. Observation with $365-\mathrm{nm}$ excitation revealed that EPS were brightly fluorescent and always emerged away from their star vessel. Midproximal segments were darker and closer to the star vessel which was surrounded by the darkest LPS. Decreasing luminal $\mathrm{HCO}_{3}^{-}$from 15 to $0 \mathrm{mM}$ lowered $\mathrm{pH}_{\mathrm{i}}$ in both EPS and LPS, but $\mathrm{pH}_{1}$ remained more alkaline in EPS with both perfusates. Thus the axial decline in $\mathrm{pH}_{\mathrm{i}}$ along the PT is due to both luminal factors and intrinsic differences in luminal $\mathrm{H}^{+}$extrusion in PT cells.
\end{abstract}

\section{Introduction}

Maintenance of acid-base homeostasis depends on the ability of the proximal convoluted tubule to reabsorb most of filtered $\mathrm{HCO}_{3}^{-}$by a process that involves $\mathrm{H}^{+}$secretion into the tubular lumen. Several studies have shown that $\mathrm{HCO}_{3}^{-}$reabsorption does not proceed at the same rate along the proximal convoluted tubule (1-4). In all these reports the magnitude of $\mathrm{HCO}_{3}^{-}$reabsorption is greater in early than in late proximal segments. Because $\mathrm{HCO}_{3}^{-}$reabsorption increases as a function of luminal $\mathrm{HCO}_{3}^{-}$concentration (5), augmented $\mathrm{HCO}_{3}^{-}$reabsorption in the early proximal tubule could be explained by the higher luminal $\mathrm{HCO}_{3}^{-}$concentration in early segments compared with late proximal segments. Recently, however, studies by Alpern et al. $(6,7)$ in the Munich-Wistar rat have argued that the axial heterogeneity for $\mathrm{HCO}_{3}^{-}$reabsorption in the proximal tubule cannot be accounted for solely on the basis of differences in luminal $\mathrm{HCO}_{3}^{-}$concentration. In the early proximal tubule $\mathrm{HCO}_{3}^{-}$reabsorption was about twofold greater than that in the late proximal tubule when microperfused with a $\mathrm{HCO}_{3}^{-}$concentration equal to that in glomerular ultrafiltrate. The mechanism responsible for this axial heterogeneity in proximal $\mathrm{HCO}_{3}^{-}$reabsorption $\left(\mathrm{H}^{+}\right.$ secretion) is unknown.

Results of this study were reported in part at the April meeting of the American Federation for Clinical Research, 1985 and at the 18th Annual Meeting of the American Society of Nephrology, 1985.

Address reprint requests to Dr. Pastoriza-Munoz, Building 61, VA Medical Center, Northport, NY 11768.

Received for publication 22 April 1986 and in revised form 23 December 1986.

The Journal of Clinical Investigation, Inc.

Volume 80, July 1987, 207-215
The purpose of the present study was to develop a technique for measuring intracellular $\mathrm{pH}\left(\mathrm{pH}_{\mathrm{i}}\right)^{1}$ in the superficial proximal tubule, and to examine the importance of $\mathrm{pH}_{\mathrm{i}}$ in explaining $\mathrm{HCO}_{3}^{-}$reabsorption in this nephron segment. To accomplish this, cells of the proximal tubular epithelium were loaded with the pH-sensitive fluoroprobe 4-methylumbelliferone (4MU), and observed by epifluorescence microscopy. The results demonstrate that under free-flow conditions there is a declining profile of $\mathrm{pH}_{\mathrm{i}}$ along the entire superficial proximal tubule. To investigate the etiology of this $\mathrm{pH}_{\mathrm{i}}$ heterogeneity, early and late proximal segments were microperfused in situ. At equal $\mathrm{HCO}_{3}^{-}$concentrations, late segments were again acidic relative to proximal segments, supporting the results of fluorescence under free-flow conditions. In both early and late proximal segments, $\mathrm{pH}_{\mathrm{i}}$ fell when $\mathrm{HCO}_{3}^{-}$in the perfusate was reduced. These results demonstrate that the declining $\mathrm{pH}_{\mathrm{i}}$ profile along the proximal tubule reflects both luminal factors and intrinsic differences in the mechanisms of $\mathrm{pH}_{\mathrm{i}}$ regulation in early compared with late tubular cells.

\section{Methods}

Sprague-Dawley rats maintained on normal rat chow and weighing 220$280 \mathrm{~g}$ were anesthetized by an i.p. injection of sodium nembutal $(50 \mathrm{mg} /$ $\mathrm{kg}$ ). Rats were placed on a feedback-regulated heating table. A tracheostomy was performed and catheters were inserted in the external jugular vein for the administration of $0.85 \% \mathrm{NaCl}$ solution at a rate of $40 \mu \mathrm{l}$ / $\mathrm{min}$, and in the femoral artery for blood pressure monitoring and arterial blood gas measurement. The left kidney was exposed for micropuncture as previously described (8) and catheters inserted in both ureters for urine collection.

\section{Nephron segment identification}

Random proximal segments were selected by transit time measurement after i.v. injection of FD\&C green dye. Proximal sites belonging to the same nephron were identified by intratubular injection of isotonic saline stained with FD\&C green dye into random proximal convolutions with a 6-7- $\mu \mathrm{m}$ outer tip diameter pipette. Early proximal sites were selected by retrograde injection while mid- and late proximal sites were identified by noting the sequence of appearance of dye in downstream convolutions. Localization was confirmed by i.v. bolus injection of dye. Early distal convolutions were selected as those convolutions in which dye first appeared after its transit through the loop of Henle, whereas late distal convolutions were chosen as those in which the dye appeared last before reaching the ureter.

\section{Cell loading}

Delivery of fluoroprobes (4-methylumberiferyl acetate [4MUA], 5-6 carboxyfluorescein diacetate [CFA ${ }_{2}$ ]) (Molecular Probes, Inc., Junction City, OR) to the tubular epithelium was accomplished by renal superfusion or intratubular administration. These acetylated derivatives of $4 \mathrm{MU}$ and 5-6 carboxyfluorescein (CF) have higher lipid solubility and exhibit min-

1. Abbreviations used in this paper: CF, 5-6 carboxyfluorescein; CFA 5-6 carboxyfluorescein diacetate; $4 \mathrm{MU}, 4$-methylumbelliferone; 4MUA, 4-methylumbelliferyl acetate; $\mathrm{pH}_{\mathrm{i}}$, intracellular $\mathrm{pH}$. 
imal (4MUA) or negligible (CFA $)$ fluorescence compared with the fluorescent compounds.

\section{Superfusion studies}

The kidney surface with capsule intact was superfused via 0.023-inch polyethylene tubing. An ultrathin layer was formed by perfusing under a submicron thick sheet of copolymer (Dow Chemical Co., Midland, MI) placed over the cortical surface. The composition of the superfusate was (millimolar): $\mathrm{NaCl} 145, \mathrm{CaCl}_{2} 2.5, \mathrm{MgSO}_{4} 1.8, \mathrm{KCl} 4.5$, and Tris 4.5. 4MUA and $\mathrm{CFA}_{2}$ were first dissolved in methanol and then added to the superfusate to achieve concentrations of $2 \times 10^{-4} \mathrm{M}$ (1\% methanol). A superfusate $\mathrm{pH}$ of 6.5 was chosen to minimize the fluorescence signal from the superfusate layer over the renal surface. With this procedure, the contribution of this fluid layer under the copolymer sheet to the overall signal measured over the tubular epithelium was $<10 \%$ as assessed by comparing fluorescence before and after flushing the renal surface with superfusate devoid of fluoroprobe. Measurements to be reported here were not corrected for the contribution of the superfusate fluid layer. Superfusates were bubbled with $7 \% \mathrm{CO}_{2}$ to obtain a $\mathrm{PCO}_{2}$ of 60 $\mathrm{mm} \mathrm{Hg}$, similar to that in superficial rat renal cortex (9). Appropriate amounts of $\mathrm{NaHCO}_{3}$ were added to the perfusate to maintain $\mathrm{pH}$ constant at 6.5.

\section{Intratubular administration}

Studies with $\mathrm{CFA}_{2}$ by luminal microperfusion. Early and late proximal convolutions of the same nephron were injected manually with Tris buffer containing $10^{-4} \mathrm{M}$ of the fluoroprobe for periods of 2-3 min and at a rate low enough to avoid dilatation of the lumen.

Studies with $4 M U$ by luminal microperfusion. Early proximal and late proximal convolutions belonging to the same nephron were identified as described above. An 8-10- $\mu \mathrm{m}$ outside diameter pipette was inserted in the distal end of an early proximal convolution and perfusion carried out at $40 \mathrm{nl} / \mathrm{min}$ using a modified Hampel pump. Two perfusates were used: $15 \mathrm{mM} \mathrm{HCO}_{3}^{-}$(high $\mathrm{HCO}_{3}^{-}$), $\mathrm{pH} 7.0$, and $0 \mathrm{mM} \mathrm{HCO}_{3}^{-}$(low $\left.\mathrm{HCO}_{3}^{-}\right)$, pH 5.6. Both perfusates were bubbled with $7 \% \mathrm{CO}_{2}(60 \mathrm{~mm}$ $\mathrm{Hg}$ ) and contained (millimolar) $4.5 \mathrm{KCl}, 2.5 \mathrm{CaCl}_{2}$, and $1.8 \mathrm{MgCl}_{2}$. Appropriate amounts of $\mathrm{NaCl}$ were added to achieve a $\mathrm{Na}$ concentration of $145 \mathrm{mM}$. 4MU at a concentration of $10^{-3} \mathrm{M}$ dissolved in $1 \%$ methanol or $1 \%$ dimethyl sulfoxide (DMSO) was added to perfusates containing FD\&C green dye or nigrosin (1\%). The proximal end of the convolution was then entered with a 10-12- $\mu \mathrm{m}$ outside diameter pipette filled with Sudan Black-stained bone wax and a short wax column introduced using a Wells hydraulic microdrive (Trent Wells, Southgate, CA) to interrupt tubular filtrate flow. After fluorescence measurements were obtained, the perfusion pipette was removed and inserted into the late proximal convolution of the same nephron and perfusion carried out at this site. In some nephrons early and late proximal convolutions were perfused sequentially with the two $\mathrm{HCO}_{3}^{-}$-containing perfusates. In this case early and late proximal convolutions were reentered with a separate pipette containing the second perfusate. In some cases sequential perfusion was performed using a double-barreled pipette filled with the two bicarbonate perfusates. $\mathrm{pH}$ and $\mathrm{PCO}_{2}$ were measured in arterial blood, superfusates, and luminal perfusates using a Corning 150 blood gas analyzer (Corning Medical, Medfield, MA).

\section{Fluorescence measurements and optical system}

For fluorescence measurements the rat and heating table were mounted on a modified stage of a Labophot microscope (Nikon Inc., Garden City, NY) fitted with an epifluorescence attachment and a trinocular body tube. A 100-W mercury lamp was used as the light source. The epifluorescence attachment was modified to accommodate appropriate bandpass excitation filters (Ditric Optics, Hudson, MA) and Inconel-coated quartz windows (Corion Corp., Holliston, MA) to decrease the intensity of excitation light when indicated. In the studies with 4MUA, light was first filtered using a UG 11 filter (Ealing Corp., S. Natick, MA) and narrow band excitation was then obtained using 365- and 334-nm filters. For 365-nm excitation a neutral-density filter with $1 \%$ transmittance was used. Because the intensity of 334-nm light was $\sim 100$-fold less than that at $365 \mathrm{~nm}$, a neutral density filter was not used for 334-nm excitation. Epillumination was achieved using a dichroic mirror and barrier filter assembly (400- and 410-nm transmittance, respectively) and a $\times 20 \mathrm{Ni}-$ kon-Fluor objective. In the studies with $\mathrm{CFA}_{2}$ excitation was performed with 460- and 490-nm bandpass filters using a Nikon $B$ filter cube cassette and $\times 20 \mathrm{CF}$ objective.

The optical system for both 4MUA and $\mathrm{CFA}_{2}$ studies included a $\times 2.5$ relay lens inserted in the phototube of the microscope head. Fluorescence was measured using a Farrand microscope spectrum analyzer (Farrand Optical Co., Valhalla, NY) with target spotting capability mounted on the phototube of the microscope. Emission wavelengths corresponding to maximal fluorescence intensity were 460 and $535 \mathrm{~nm}$ for $4 \mathrm{MU}$ and $\mathrm{CF}$, respectively. Magnification of the combined optical system including lenses in the Farrand analyzer was $\times 625$. A $0.13-\mathrm{mm}$ pinhole and a 15-nm slit were placed in the apertures of the emissiongrating monocromator and photomultiplier tube, respectively. With the $\times 20$ objective, the area from which fluorescence was measured was 4 $\mu \mathrm{m}^{2}$, allowing fluorescence measurements to be localized just to the tubular epithelium while avoiding the lumen and peritubular capillaries. To further ensure that measurements of epithelial fluorescence were not contaminated by fluorescence from luminal dye, we tested the ability of our system to reject a luminal fluorescence signal when the field of measurement was localized over the epithelium. Random proximal convolutions were perfused with a fluorescent but cell-impermeant compound, fluorescein isothiocyanate-labeled dextran $(70,000 \mathrm{~mol} \mathrm{wt}$, Sigma Chemical Co., St. Louis, MO). Moving the target spotter from the lumen to the epithelium caused fluorescence to fall abruptly to background level.

Exposure to excitation light, especially at ultraviolet wavelengths, for periods in excess of $5 \mathrm{~min}$ consistently resulted in damage. This was manifested in order of increasing severity by prolonged tubular transit times, decrease in capillary blood flow, and cloudiness of the epithelium. In our studies total exposure times were therefore kept under $1 \mathrm{~min}$ and light intensity reduced by use of neutral density filters to levels just high enough to allow measurement in the most sensitive scale of the photometer. As an additional precaution measurements were discarded if tubular transit times taken at the end of the study were prolonged by $>1 \mathrm{~s}$ in early proximal and $2 \mathrm{~s}$ in late proximal convolutions.

\section{In vitro calibration}

Solutions containing $4 \mathrm{MU}$ or $\mathrm{CF}$ (the nonesterified free acids) were titrated to various $\mathrm{pH}$ values and fluorescence emission measured using the same optical system as that for measurement of epithelial fluorescence. To obviate bleaching, fluorescence was measured from the solutions as they were gravity perfused through $55 \mu \mathrm{M}$ quartz capillary tubing.

\section{$4 M U$ in vivo calibration}

In wax-blocked nephrons from a separate group of rats, lumen and capillaries of early and late proximal convolutions were perfused with a solution of the following composition (millimolar): 25 Hepes, 60 $\mathrm{K}_{2} \mathrm{HPO}_{4}$, and pH adjusted to $6.8,7.1$, or $7.4\left(\mathrm{PCO}_{2} 60 \mathrm{~mm} \mathrm{Hg}\right.$, appropriate amount of $\mathrm{NaHCO}_{3}$ added for each $\mathrm{pH}$ value) as reported by Alpern (10). Perfusates contained nigericin $(10 \mu \mathrm{M})$ a $\mathrm{K}^{+} / \mathrm{H}^{+}$antiporter. $4 \mathrm{MU}\left(10^{-3} \mathrm{M}\right)$ was added to the luminal perfusate. $\mathrm{K}^{+}$concentration was chosen to approximate $\mathrm{K}^{+}$activity reported in proximal tubular cells (11). Fluorescence measurements were obtained 5-10 min after initiation of perfusion. Calibration did not differ in early and late proximal convolutions. Furthermore, the calibration curve overlapped with that obtained in vitro.

\section{pH sensitivity of $4 M U$ fluorescence}

At excitation wavelengths of $320-340 \mathrm{~nm}$, the fluorescence of $4 \mathrm{MU}$ is relatively pH-insensitive whereas a marked increase is observed as a function of $\mathrm{pH}(6.5-8.0)$ at wavelengths of $350-380 \mathrm{~nm}$. We chose 334 and $365 \mathrm{~nm}$ as pH-insensitive and -sensitive wavelengths, taking advantage of the intense emission of the mercury lamp at these two wavelengths, and the availability of the corresponding bandpass filters. Changes in fluorescence as a function of $\mathrm{pH}$ were expressed as the ratio of 365/334 $\mathrm{nm}$ to correct for changes in fluoroprobe concentration and light intensity 
(Fig. 1 and Graber et al. [12, 13]). Ratio was unaltered by a fivefold increase in light intensity and a threefold increase or decrease in fluoroprobe concentration. $4 \mathrm{MU}$ had no apparent toxic effects on tubular function: Continuous superfusion for up to $4 \mathrm{~h}$, a period far greater than that required to perform the measurements reported here, failed to show changes in tubular morphology, tubular transit times, or arterial blood gases.

\section{pH sensitivity of CF fluorescence}

We have previously shown that an increase in $\mathrm{pH}$ causes increase in the fluorescence of $\mathrm{CF}$ which is more marked at excitation wavelengths near $490 \mathrm{~nm}$ than at shorter wavelengths (430-460 nm [13]). We chose 490 and $460 \mathrm{~nm}$ as the $\mathrm{pH}$-sensitive and relatively $\mathrm{pH}$-insensitive wavelengths, respectively. A ratio of fluorescence at these two excitation wavelengths is linearly related to $\mathrm{pH}(13)$.

Statistical comparisons were made using Student's $t$ test for paired or unpaired data, as appropriate.

\section{Results}

\section{Qualitative observations}

$4 M U A$. Fig. 2 (diagram I) illustrates the fluorescence appearance of a star vessel complex during 4MUA superfusion under 365nm excitation. Three star vessels are shown surfacing in close proximity to one another surrounded by convolutions belonging to several nephrons. Shown on the right is a limited drawing of an adjacent star vessel complex. Star vessels and peritubular capillaries appear totally dark, reflecting the known absorption by hemoglobin of the excitation wavelengths used ( 334 and 365 $\mathrm{nm}$ ) to elicit 4MU fluorescence (14). In small-diameter capillaries, erythrocytes flow in single file with a stop-and-go pattern. Fluorescence of $4 \mathrm{MU}$ in plasma is seen between clumps of red cells. Over a given point capillary fluorescence is intermittent related to interruptions in red cell flow. Areas where these capillaries crossed the epithelium were easily identified and avoided. The surface nephron convolutions differ strikingly in their fluorescence intensity, a pattern which is also observed during perfusion of peritubular capillaries with a solution devoid of fluoroprobe. Some convolutions are bright blue, others appear medium bright whereas still others exhibit dark blue fluorescence. In all convolutions, fluorescence is highly homogeneous and is not affected by light exposure (photobleaching), and tubular lumens are minimally visible, if at all. There is no evidence of increased fluorescence localized to the peritubular space. Convolutions with similar fluorescence intensity group themselves together forming discrete areas. These areas, in turn, adopt a highly organized pattern. Clusters of bright convolutions are far-

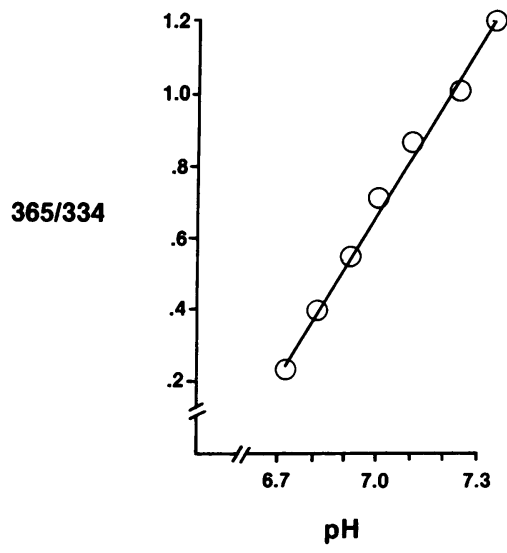

Figure 1. In vitro relationship between 365 / 334-nm fluorescence intensity ratio and $\mathrm{pH}$. thest from the star vessels and form ridges that tend to encircle the latter. In some cases a full crown effect is seen. Darkest convolutions are found in areas near star vessels. Convolutions with moderate brightness are located between the bright and dark convolutions. By the transit time technique bright convolutions are always early proximal segments. Convolutions with intermediate fluorescence correspond to midproximal segments, whereas dark convolutions represent late proximal segments. Distal segments appear dark with early distal segments usually occupying a more central position, near the star vessels, than late distal segments (diagram II). In contrast to these observations at $365 \mathrm{~nm}$, using pH-insensitive excitation at $334 \mathrm{~nm}$, all surface convolutions have approximately the same fluorescence intensity.

The above anatomical findings indicate that there is a high level of organization of proximal convoluted tubules on the renal surface. Two types of surfacing patterns were identified (Fig. 2, diagrams I-III). In some nephrons, the early proximal tubule reaches the kidney surface and occupies a position farthest from the star vessel (nephrons $A, B, C, F, G$ in diagram II and nephrons $H, I, K, L, M, P$ in diagram III). These early segments lie in clusters together with early proximal segments from adjacent nephrons. Late proximal convolutions are seen surrounding a star vessel whereas midproximal convolutions occupy an intermediate position between early and late proximal convolutions. In other nephrons ( $D$ and $E$ in diagram II and $J, N, O$ in diagram III), the early proximal tubule lies entirely below the renal surface. In these nephrons the first segments to be seen on the renal surface are midproximal, and these lie in areas medial to that occupied by surface early proximal convolutions from other nephrons. This orderly surfacing pattern results in the concentric areas of decreasing fluorescence.

$\mathrm{CFA}_{2}$. After 3-5 min of superfusion, yellowish-green fluorescence of $\mathrm{CF}$ is observed in the epithelium of proximal and distal convolutions. The fluorescence appearance is highly nonhomogeneous with striking granularity primarily localized to the basolateral margin. This pattern was more evident in distal convolutions than in proximal segments. Visually, the CF fluorescence is of similar intensity at different proximal tubular segments and the crown effect noted with 4MUA is not observed. Because of the marked granularity of fluorescence and uncertainty as to its meaning, quantitative fluorescence measurements were not obtained with this type of loading. For this purpose we resorted to cell loading by intratubular administration of $\mathrm{CFA}_{2}$. By this approach CF fluorescence is nearly homogeneous (see below).

\section{Fluorescence intensity measurements in $4 M U$ superfusion studies}

The 365/334-nm fluorescence ratios along the proximal and distal tubule are shown in Table I. In the proximal convoluted tubule the 365/334-nm ratio decreased significantly from 0.85 $\left(\mathrm{pH}_{\mathrm{i}} 7.14\right)$ in early proximal convolutions to $0.65\left(\mathrm{pH}_{\mathrm{i}} 6.96\right)$ in midproximal and fell farther to $0.55\left(\mathrm{pH}_{\mathrm{i}} 6.87\right)$ in late proximal convolutions. These differences were due to significant changes in fluorescence at $365 \mathrm{~nm}$, whereas fluorescence at $334 \mathrm{~nm}$ was essentially the same at the different nephron sites (data not shown). These results demonstrate an axial decline in $\mathrm{pH}_{\mathrm{i}}$ in this nephron segment. The 365/334-nm ratio in early distal and late distal convolutions was not significantly different $(0.20>P$ $>0.10$ ) and is similar to the ratios in late proximal convolutions.

To further validate the findings in random convolutions; 

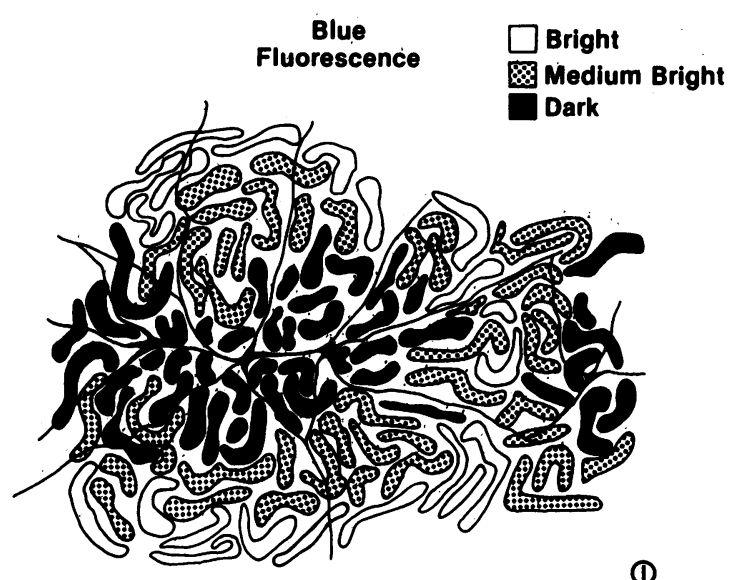

(1)
* Early Distal

* Mid Distal

*** Late Distal

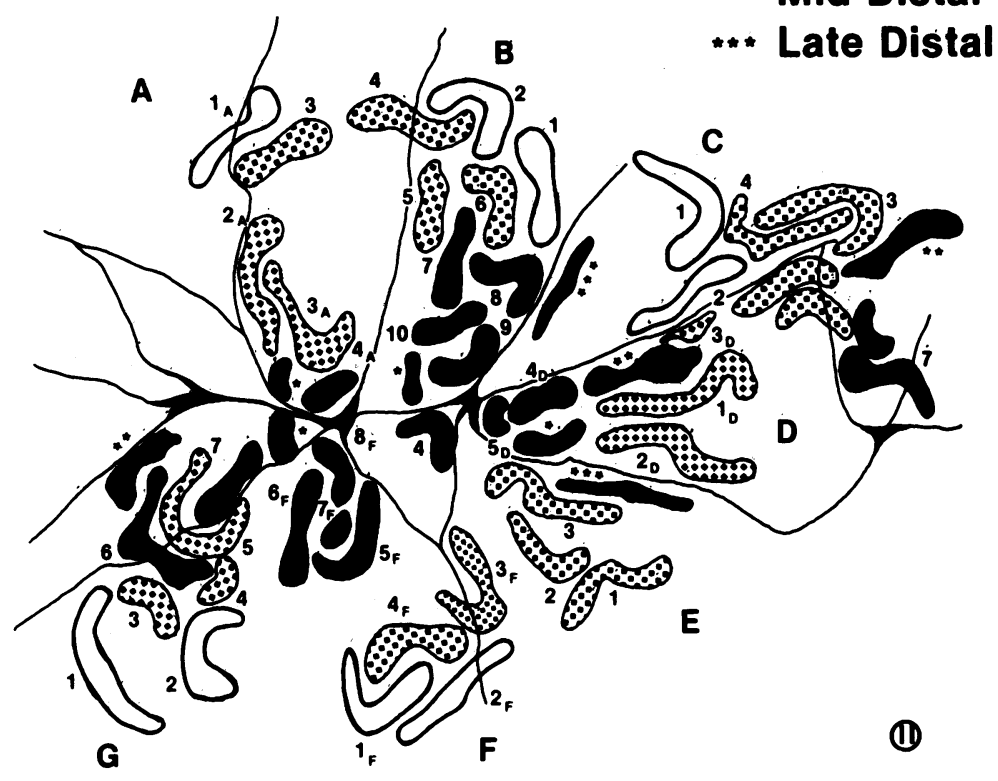

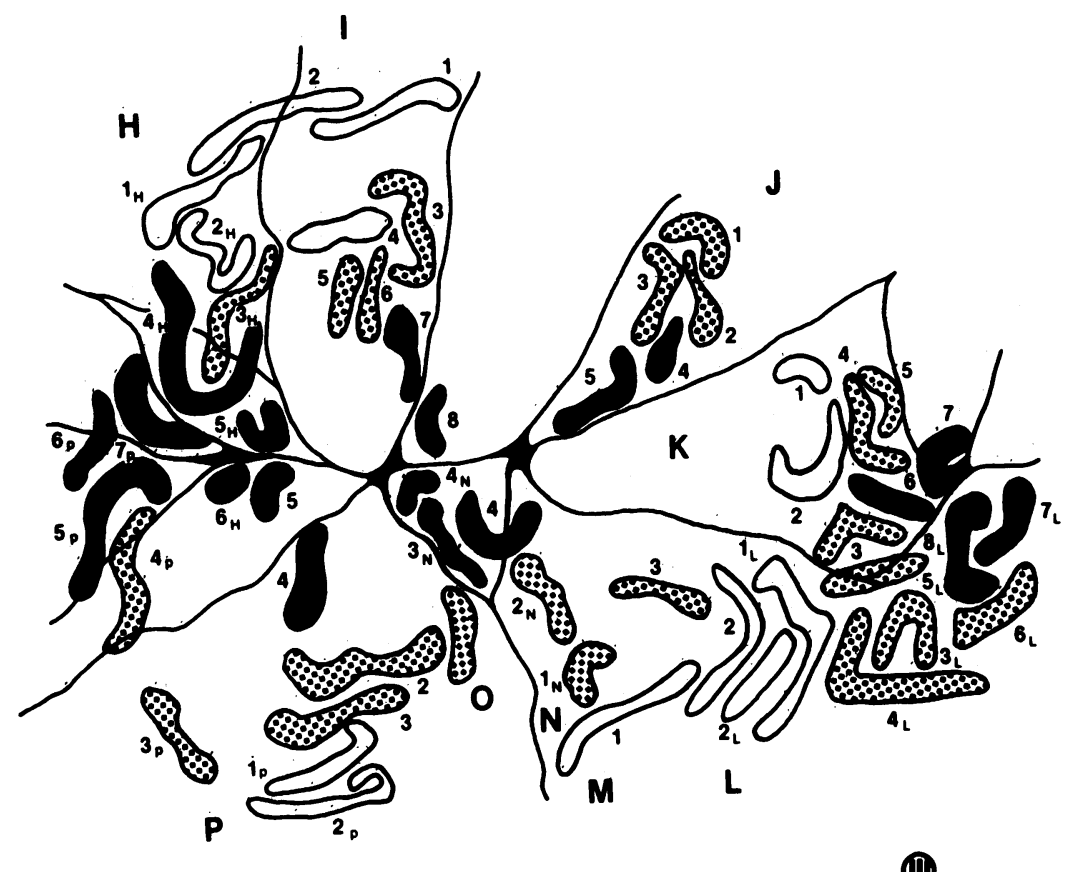

(1).

Figure 2. Diagram of an area of renal surface as seen during superfusion with 4MUA using $365 \mathrm{~nm}$ excitation. (I) Identification of sites along proximal and distal convoluted tubules was performed by transit times during i.v. bolus injections of FD\&C green dye. Early proximal convolutions have bright blue fluorescence, midproximal show medium bright fluorescence, and late proximal convolutions exhibited dark blue fluorescence. Nephron identification (II and III) was carried out by intratubular injection of FD\&C green dye. Letters refer to individual nephrons. Numbers rank surface convolutions from the first to last.

measurements were obtained sequentially in proximal convolutions belonging to the same nephron and grouped based on transit time as early $(3 \pm 0.6 \mathrm{~s})$, mid $(7 \pm 1.2 \mathrm{~s})$ and late $(11 \pm 1.4$ s) convolutions (Table I). The results are qualitatively and quantitatively similar to those obtained in random convolutions.

Fluorescence measurements during luminal perfusion

Background epithelial autofluorescence was homogeneous and relatively low at the excitation wavelengths used for the 4MUA and $\mathrm{CFA}_{2}$ studies and did not significantly differ at various sites along the nephron. $4 \mathrm{MU}$ and $\mathrm{CF}$ epithelial fluorescence was at least 10-fold greater than autofluorescence. Ratios reported here were corrected for the measured background fluorescence.
$4 M U$. This series of studies was undertaken with two purposes. First, we wished to further validate the results obtained during superfusion by measuring the fluorescence ratio under conditions where fluoroprobe is solely localized to the epithelium of the injected nephron. Second, we were interested in examining the dependency of $\mathrm{pH}_{\mathrm{i}}$ on luminal $\mathrm{HCO}_{3}^{-}$concentration. 4MU was used in place of 4MUA to avoid the possibility of cell acidification consequent to intracellular 4MUA hydrolysis. Within a few seconds after the initiation of luminal perfusion, blue fluorescence was appreciated in the tubular epithelium of the convolution being perfused. Fluorescence was completely homogeneous. The leak rate of $4 \mathrm{MU}$ was very fast, with fluorescence returning to near background levels within 5-10 s of discontin- 
Table I. Profile of Fluorescence Ratio (365/334) and $\mathrm{pH}_{i}$ along the Nephron under Free-flow Conditions

\begin{tabular}{|c|c|c|c|c|c|}
\hline & \multicolumn{3}{|c|}{ Proximal tubule } & \multicolumn{2}{|l|}{ Distal tubule } \\
\hline & Early & Mid & Late & Early & Late \\
\hline Random convolutions & (18) & (16) & (10) & (12) & (5) \\
\hline $365 / 334$ & $0.85 \pm 0.03$ & $0.65 \pm 0.03^{*}$ & $0.55 \pm 0.02^{\ddagger}$ & $0.59 \pm 0.03$ & $0.49 \pm 0.05$ \\
\hline $\mathrm{pH}_{\mathrm{i}}$ & $7.14 \pm 0.02$ & $6.96 \pm 0.02$ & $6.87 \pm 0.01$ & $6.91 \pm 0.02$ & $6.82 \pm 0.04$ \\
\hline Same nephron & (5) & (5) & (5) & & \\
\hline $365 / 334$ & $0.83 \pm 0.03$ & $0.69 \pm 0.03^{8}$ & $0.57 \pm 0.02^{\prime \prime}$ & & \\
\hline $\mathrm{pH}_{\mathrm{i}}$ & $7.12 \pm 0.02$ & $6.99 \pm 0.02$ & $6.89 \pm 0.01$ & & \\
\hline
\end{tabular}

Values are means \pm SEM. Numbers in parentheses denote number of observations. Values are not significantly different from those at preceding site except where noted. ${ }^{*} P<0.01$. ${ }^{\ddagger} P<0.02$. $P<0.05$. $" P<0.002$. $\mathrm{pH}_{\mathrm{i}}$ values were calculated from in vivo calibration in a separate group of rats.

uing perfusion. In measuring epithelial fluorescence care was taken to avoid those areas where capillaries crossed the epithelium. Uptake of $4 \mathrm{MU}$ in convolutions adjacent to the one being perfused was barely appreciable, if at all. Significant fluorescence could be seen only if a leak at the puncture site was present as evidenced by appearance of FD\&C green dye outside of the punctured convolution. Fluorescence from convolutions below the surface could not be detected. The quantitative results using luminal perfusion of $4 \mathrm{MU}$ are shown in Table II. To determine the magnitude of the change in $\mathrm{pH}_{\mathrm{i}}$ after changes in luminal $\mathrm{HCO}_{3}^{-}$concentration studies were repeated in a separate group of rats in which in vivo calibration analysis was also obtained. Results were very similar to those calculated for the 365/334$\mathrm{nm}$ ratios reported here (see legend to Table II). In random early and late proximal convolutions, decreasing $\mathrm{HCO}_{3}^{-}$concentration from 15 to $0 \mathrm{mM}$ caused the $365 / 334-\mathrm{nm}$ ratio to decrease significantly at both sites. $\mathrm{pH}_{\mathrm{i}}$ decreased from 7.23 to 7.13 in early convolutions and from 7.15 to 7.07 in late proximal convolutions. The decrease in $365 / 334-\mathrm{nm}$ ratio in early proximals $(\Delta$ $=0.11 \pm 0.04$ ratio units) was similar to that in late proximal convolutions $(\Delta=0.08 \pm 0.03)$. A second finding is that the $365 /$ 334-nm ratio and $\mathrm{pH}_{\mathrm{i}}$ are significantly higher in early proximal than in late proximal convolutions belonging to the same nephron with both 15 and $0 \mathrm{mM} \mathrm{HCO}_{3}^{-}$perfusates. These results indicate that regardless of the luminal $\mathrm{HCO}_{3}^{-}$concentration $\mathrm{pH}_{\mathrm{i}}$ is more alkaline in early than in late proximal convolutions, and that at both sites cell $\mathrm{pH}$ is altered by variations in luminal $\mathrm{HCO}_{3}^{-}$concentration or $\mathrm{pH}$.

$C F A_{2}$. To further validate the results obtained with $4 \mathrm{MU}$ in free-flowing nephrons, the $\mathrm{pH}$ sensitive 490/460-nm fluorescence ratio was measured under free-flow conditions in early and late proximal convolutions loaded with $\mathrm{CFA}_{2}$. 1-2 min after initiation of luminal perfusion, bright yellow-green epithelial fluorescence was noted in the convolution being injected. Fluorescence was only faintly granular. The leak rate of CF was relatively rapid with a $t_{1 / 2}$ of 2-3 min in early proximal and 5-7 min in late proximal convolutions. The 490/460-nm fluorescence ratio was measured within $3 \mathrm{~min}$ after cessation of luminal perfusion in early and late proximal convolutions (six nephrons). Early proximal convolutions were significantly more alkaline than late

Table II. Effect of Luminal $\mathrm{HCO}_{3}^{-}$on Epithelial Fluorescence Ratio (365/334) and pH in Random Early and Late Proximal Convolutions, Paired by Perfusate, and in Convolutions Belonging to Same Nephron, Paired by Site

\begin{tabular}{|c|c|c|c|c|}
\hline \multirow[b]{2}{*}{$\mathrm{HCO}_{3}^{-}$} & \multicolumn{2}{|l|}{ Early proximal } & \multicolumn{2}{|l|}{ Late proximal } \\
\hline & $15 \mathrm{mM}$ & $0 \mathrm{mM}$ & $15 \mathrm{mM}$ & $0 \mathrm{mM}$ \\
\hline \multicolumn{5}{|c|}{ Random convolutions } \\
\hline $365 / 334$ & $0.95 \pm 0.05$ & $0.84 \pm 0.05^{*}$ & $0.86 \pm 0.06$ & $0.78 \pm 0.06^{*}$ \\
\hline $\mathrm{pH}_{\mathrm{i}}$ & $\begin{array}{l}7.23 \pm 0.04 \\
(n=7)\end{array}$ & $\begin{array}{l}7.13 \pm 0.04 \\
(n=7)\end{array}$ & $\begin{array}{l}7.15 \pm 0.05 \\
(n=5)\end{array}$ & $\begin{array}{l}7.07 \pm 0.05 \\
(n=5)\end{array}$ \\
\hline \multicolumn{5}{|c|}{ Same nephron } \\
\hline $365 / 334$ & $0.94 \pm 0.05$ & & $0.86 \pm 0.06^{\ddagger}$ & \\
\hline $\mathrm{pH}_{\mathrm{i}}$ & $\begin{array}{l}7.22 \pm 0.04 \\
(n=10)\end{array}$ & & $\begin{array}{l}7.15 \pm 0.05 \\
(n=10)\end{array}$ & \\
\hline $365 / 334$ & & $0.86 \pm 0.06$ & & $0.74 \pm 0.06^{8}$ \\
\hline $\mathrm{pH}_{\mathrm{i}}$ & & $\begin{array}{l}7.15 \pm 0.05 \\
(n=7)\end{array}$ & & $\begin{array}{l}7.04 \pm 0.05 \\
(n=7)\end{array}$ \\
\hline
\end{tabular}

Values are means \pm SEM. $n=$ number of observations. $* P<0.05$ compared with $15 \mathrm{mM}$ in same convolution. $\mathrm{pH}_{\mathrm{i}}$ values were calculated from in vivo calibration in a separate group of rats. In this latter group $\mathrm{pH}_{\mathrm{i}}$ values as a function of luminal $\mathrm{HCO}_{3}^{-}$were for early proximal cells, $7.26(15$ $\mathrm{mM}), 7.15(0 \mathrm{mM})$; and for late proximal cells, $7.15(15 \mathrm{mM})$ and $7.06(0 \mathrm{mM}){ }^{\ddagger} P<0.02$ and $8<0.05$ compared with early proximal in the same nephron. 
proximal convolutions as evidenced by a higher $490 / 460-\mathrm{nm}$ fluorescence ratio in the former $(0.500 \pm 0.016$ vs. $0.440 \pm 0.018$, $P<0.02$ ). To ensure that these measurements were not influenced by the falling intracellular concentration of fluoroprobe, in a separate series of studies 490/460-nm ratios were measured immediately and again 3-4 min after epithelial loading. In paired comparisons, sequential ratios were not significantly different (data not shown).

\section{Discussion}

Two major findings of these studies are $(a)$ the demonstration of a high level of organization in the proximal convolutions on the cortical surface, and $(b)$ the presence of an axial $\mathrm{pH}_{\mathrm{i}}$ gradient along this segment. These two observations account for the striking concentric differences in $\mathrm{pH}_{\mathrm{i}}$ expressed on the kidney surface.

Intracellular pH methodology. 4MU has been previously used to measure cell $\mathrm{pH}$ in various tissues (15-17) and recently by us in the turtle bladder (12). We used the nonfluorescent derivative of 4MU, 4MUA, which is lipid soluble and readily enters cells where it is converted by cytosolic esterases to the more polar and fluorescent compound 4MU. Similar considerations apply to the use of $\mathrm{CFA}_{2}$ (18). 4MU fluorescence in the tubular epithelium was completely homogeneous, suggesting that the fluoroprobe is largely localized to the cytosol and does not undergo significant intracellular compartmentalization and/or binding. In mitochondria where $\mathrm{pH}$ exceeds 7.3 , the $\mathrm{pKa}$ of $4 \mathrm{MU}$ (13), accumulation as the dissociated form might be expected but this is apparently precluded by the opposing force of the negative intramitochondrial potential. Failure to observe 4MU accumulation in other organelles may reflect restricted entry or alternatively be due to an inner filter effect created by fluoroprobe in the cytosol. Intracellular binding is also not likely to be a concern with $4 \mathrm{MU}$. This is supported by the finding that in vivo calibration overlaps with that obtained in vitro, an observation that contrasts with the findings reported by Alpern with $\left(2^{\prime}, 7^{\prime}\right)$-bis (carboxyethyl) $(5,6)$-carboxyfluorescein (10). Intracellular binding or high dye concentration may be responsible for the shift to more alkaline values of in vivo calibration compared with in vitro values (13).

Superfusion with 4MUA revealed striking differences in fluorescence intensity in the different nephron segments at 365 $\mathrm{nm}$ excitation. That this pattern reflects differences in $\mathrm{pH}_{\mathrm{i}}$ rather than concentration differences is supported by three additional findings: (a) Using the $\mathrm{pH}$-insensitive excitation wavelength of $334 \mathrm{~nm}$, fluorescence intensity is comparable along the nephron, indicating roughly equal dye concentrations in the different nephron segments. (b) The gradient of fluorescence ratios along the proximal tubule is also seen during cell loading with luminal 4MU. (c) The same gradient is demonstrable in proximal cells loaded with CF. This fluoroprobe is dissimilar from $4 \mathrm{MU}$, but also exhibits pH-sensitive fluorescence and has been used extensively for this purpose $(19,20)$. Like $4 \mathrm{MU}$, the 490/460-nm excitation ratio increases with more alkaline $\mathrm{pH}$ values. To ensure that differences in the CF fluorescence ratio represent differences in cell $\mathrm{pH}$ and not differences in dye concentration, we analyzed only those measurements with comparable fluorescence at the $\mathrm{pH}$-insensitive wavelength of $460 \mathrm{~nm}$.

We did not attempt to quantitate fluorescence ratios when CF was loaded by superfusion because the resultant fluorescence was not homogeneous and appeared to be confined to the basolateral regions of the tubule. We assume this reflects either a binding phenomenon, or accumulation of CF in alkaline spaces. The conversion of $\mathrm{CFA}_{2}$ to $\mathrm{CF}$ in the basolateral region may represent nonenzymatic hydrolysis in an alkaline environment, or catalyzed hydrolysis by esterases.

Axial profile of $\mathrm{pH}_{i}$ along the superficial proximal tubule. Intracellular $\mathrm{pH}$ in the proximal convoluted tubule of the rat has been measured by Yoshitomi and Fromter (21) with pHsensitive microelectrodes and by Alpern and Chambers $(10,22)$ using $\left(2^{\prime}, 7^{\prime}\right)$-bis (carboxyethyl) $(5,6)$-carboxyfluorescein. In these studies the possibility of differences in $\mathrm{pH}_{\mathrm{i}}$ along the proximal tubule was not examined as convolutions were selected randomly. Our results demonstrate a declining profile of cell pH from the early to late proximal tubule. This is apparent visually from the pattern of fluorescence seen with pH-sensitive $365-\mathrm{nm}$ excitation, and was confirmed quantitatively using the $365 / 334-$ $\mathrm{nm}$ fluorescence ratio during superfusion with 4MUA. $\mathrm{pH}_{\mathrm{i}}$ in midproximal convolutions, 6.96 , is somewhat more acidic than the $\mathrm{pH}_{\mathrm{i}}$ of 7.17 reported by Yoshitomi and Fromter (21) at random proximal sites. This discrepancy may reflect differences in segment selection or methodology. One potential drawback of loading by superfusion is that the extremely permeant 4MUA may enter segments below those seen on the cortex surface and thus introduce an artifact in the fluorescence measurements. Because tubular fluorescence with this technique is seen emanating exclusively from superficial tubular segments and fluorescence ratio is essentially identical at different sites in a given convolution, we believe fluorescent contamination from deeper segments is small, presumably due to the inner filter effect of $4 \mathrm{MU}$ present in the most superficial segments. To further validate the quantitations obtained during superfusion, we loaded cells instead by luminal perfusion to entirely confine the fluorescence to the single perfused convolution. The axial fall in fluorescence ratio was again seen using either $4 \mathrm{MU}$ or $\mathrm{CF}$.

Of further interest is that $\mathrm{pH}_{\mathrm{i}}$ in the distal convoluted tubule is similar to that in late proximal epithelium. Because the late distal tubule is an extension of the cortical collecting tubule, the so-called connecting tubule, we specifically looked for presence of intercalated cells. These cells are thought to mediate $\mathrm{H}^{+}$secretion in the collecting duct and have been shown to have a more alkaline $\mathrm{pH}_{\mathrm{i}}$ than the principal cells that surround them $(12,19,23)$. We were unable to detect in the distal tubule areas with increased fluorescence brightness that might represent intercalated cells. This is not very surprising because intercalated cells are few in number, and we sampled only a small number of late distal convoluted tubules.

With regard to the finding of a declining $\mathrm{pH}_{\mathrm{i}}$ profile along the proximal convoluted tubule under free flow conditions, this may simply reflect the parallel fall in luminal $\mathrm{pH}$ and $\mathrm{HCO}_{3}^{-}$ concentration present in the tubular lumen. In the early proximal tubule the more alkaline tubular fluid would favor $\mathrm{H}^{+}$secretion and alkalinization of the cell. In contrast, in late proximal cells the more acidic luminal $\mathrm{pH}$ would impose a relatively adverse gradient for $\mathrm{H}^{+}$secretion and thus lead to relatively more acidic values of $\mathrm{pH}_{\mathrm{i}}$. The luminal perfusion studies clearly implicate a role of luminal $\mathrm{HCO}_{3}^{-}$concentration on $\mathrm{pH}_{\mathrm{i}}$ in both early and late proximal segments and in this context demonstrate that the axial decline in $\mathrm{pH}_{\mathrm{i}}$ seen along the proximal tubule during freeflow conditions is in part due to the decreasing profile of $\mathrm{HCO}_{3}^{-} / \mathrm{pH}$ in this nephron segment. Decrease in $\mathrm{pH}_{\mathrm{i}}$ in early proximal and late proximal convolutions $(0.10$ and $0.08 \mathrm{pH}$ 
units, respectively) is in close agreement with the decrease in $\mathrm{pH}_{\mathrm{i}}(0.08$ units) observed by Alpern and Chambers (22) in random proximal convolutions after lowering luminal $\mathrm{HCO}_{3}^{-}$concentration from 25 to $5 \mathrm{mM}$. The above findings also establish that the fall in $\mathrm{pH}_{\mathrm{i}}$ along the proximal tubule is not due solely to a decrease in luminal $\mathrm{HCO}_{3}^{-}$concentration in this nephron segment; $\mathrm{pH}_{\mathrm{i}}$ in early proximal convolutions remains relatively alkaline compared with $\mathrm{pH}_{\mathrm{i}}$ in late convolutions when perfused with solutions having identical $\mathrm{HCO}_{3}^{-}$concentration. This latter finding must represent either an effect of the peritubular environment or an intrinsic difference in the mechanisms of $\mathrm{H}^{+}$ secretion and $\mathrm{pH}_{\mathrm{i}}$ regulation in early compared with late proximal cells. Concerning the role of the peritubular mileu, a higher cell $\mathrm{pH}$ in early proximal convolutions might be the result of diminished $\mathrm{HCO}_{3}^{-}$exit (10) if $\mathrm{HCO}_{3}^{-}$concentration in early proximal capillaries were higher than in capillaries surrounding late proximal segments. Several arguments argue against this possibility playing a major role. First, $\mathrm{HCO}_{3}^{-}$concentration in early proximal capillaries may actually be lower than in late proximal capillaries because of delivery via the countercurrent system of blood with relatively low $\mathrm{HCO}_{3}^{-}$concentration (see below). This is further emphasized by the perfusion studies using $0 \mathrm{mM} \mathrm{HCO}-$ perfusate. In this setting during early proximal perfusion addition of reabsorbate with very low $\mathrm{HCO}_{3}^{-}$concentration to mid- and late proximal capillaries should have decreased, via the countercurrent arrangement of tubular and capillary flows, early proximal capillary $\mathrm{HCO}_{3}^{-}$concentration compared with the much more limited decrease in late proximal capillary $\mathrm{HCO}_{3}^{-}$concentration during perfusion of late proximal convolutions. Lastly, it would be difficult to explain how a higher cell pH could account for the observations by Alpern et al. (6) that early proximal segments reabsorb substantially more $\mathrm{HCO}_{3}^{-}$than latter segments at equal delivered loads. We therefore conclude that the more alkaline cell $\mathrm{pH}$ in early proximal cells reflects an intrinsic difference concerning the cell itself. In this regard, a higher rate of $\mathrm{H}^{+}$secretion by the early proximal cells is the most likely explanation, and would account for both the higher acidification rates and more alkaline cell $\mathrm{pH}$. The majority of proximal acidification is thought to represent the activity of an $\mathrm{Na}^{+} / \mathrm{H}^{+}$exchanger $(24,25)$. Therefore, it is conceivable that the higher $\mathrm{pH}_{\mathrm{i}}$ in early proximal cells reflects the presence of more numerous exchangers in these cells compared with late proximal cells. Our results argue against this possibility: when the tubule lumen was perfused with acidic $0 \mathrm{mM} \mathrm{HCO}_{3}^{-}$, this would be expected to impose a lumen-to-cell $\mathrm{H}^{+}$gradient that should acidify the cell. This cellular acidification was seen at both sites, but the early cells remained more alkaline than late proximal cells. If the early cells had a greater number of $\mathrm{Na}^{+}$/ $\mathrm{H}^{+}$antiporters, one would predict these cells to become more acidic than late cells, all other factors being equal.

We must therefore propose that the early proximal cells have higher rates of $\mathrm{H}^{+}$secretion for reasons other than more $\mathrm{Na}^{+} /$ $\mathrm{H}^{+}$exchanger units. One possibility to be considered is that of a higher activity of the $\mathrm{Na}^{+} / \mathrm{H}^{+}$exchanger in early proximal convolutions. This could be accomplished by lower $\mathrm{Na}_{\mathrm{i}}$ or lesser degree of inhibition of the exchanger by cytosolic $\mathrm{OH}^{-}(26)$. It should be noted that other possibilities could also account for our findings: (a) a greater contribution from a luminal $\mathrm{H}^{+}$ATPase pump (27) (existence of such pump in the proximal tubule is, however, a highly disputed matter), $(b)$ decreased luminal cell entry of $\mathrm{H}^{+}$or $\mathrm{OH}^{-}$exit via the operation of a $\mathrm{HCl}$ symporter or $\mathrm{Cl}^{-} / \mathrm{OH}^{-}$antiporter $(28,29)$, or $(c)$ a higher met- abolic production of $\mathrm{H}^{+}$. Additional studies will be required to test these various alternatives.

Functional significance of proximal tubular organization. Our finding that late proximal convolutions are located near star vessels confirms our previous observations and those made by others (30-33). The present studies also illustrate a surfacing pattern of proximal convolutions not previously appreciated. Mid and early convolutions do not emerge randomly around late proximal convolutions. Nephrons with early proximal convolutions on the surface appear at points further away from their star vessel. Midproximal convolutions from nephrons with or without early convolution on the surface emerge medial to early proximal convolutions. Another significant organizational feature is that early convolutions from separate nephrons either belonging to the same or an adjacent star vessel complex join together forming an outer crown which exhibits bright blue fluorescence by $4 \mathrm{MU}$ centered around the star vessel complex. Likewise, segregation of mid- and late proximal convolutions into discrete areas results in concentric areas of decreasing fluorescence brightness with $4 \mathrm{MU}$. The surfacing pattern of early proximal convolutions suggested to us that in superficial nephrons the initial portion of the proximal tubule must move away from its own glomerulus to later emerge in the outer region of the star vessel complex. This unfolding pattern of early proximal tubule has been shown in deeper cortical nephrons by Weinstein and Szyjewicz (33). The folding back of the proximal tubule toward its star vessel creates a countercurrent pattern of tubular fluid and capillary flows on the cortical surface. Our findings clearly establish that this arrangement does not only involve late convolutions as suggested by other investigators $(31,33)$ but also applies to early and midproximal convolutions. It should be noted that although this pattern strictly applies only to the tops of superficial convolutions, it is also applicable to those portions that lie below the surface in so far as the predominant direction of flow is still oriented toward the star vessel. We also propose that in addition to this surface countercurrent system there is a vertical countercurrent pattern that involves the initial portion of the proximal tubule (Fig. 3). The vascular portion of this system is composed of peritubular capillaries derived from penetrating branches of surface capillaries and draining into the interlobular vein located below the point where the proximal tubule folds back toward its own star vessel $(31,33)$.

We further propose that this arrangement of countercurrent flow systems may be important in regulating solute reabsorption in the proximal convoluted tubule in superficial nephrons. In the very early proximal tubule preferential $\mathrm{HCO}_{3}^{-}$reabsorption over $\mathrm{Cl}^{-}$decreases luminal $\mathrm{HCO}_{3}^{-}$concentration and increases that of $\mathrm{Cl}^{-}$. In peritubular capillaries this process will be expected to increase $\mathrm{HCO}_{3}^{-}$concentration and decrease $\mathrm{Cl}^{-}$concentration. The vertical countercurrent system may be important in facilitating $\mathrm{HCO}_{3}^{-}$reabsorption by delivering blood with a relatively low $\mathrm{HCO}_{3}^{-}$concentration which will reduce peritubular $\mathrm{HCO}_{3}^{-}$ concentration. In this fashion a relatively high $\mathrm{Cl}^{-}$concentration gradient (lumen to blood) will be generated, an effect which is a critical driving force for $\mathrm{Cl}^{-}$reabsorption in mid- and late proximal segments. In these segments the superficial countercurrent system delivers star vessel blood which has a lower $\mathrm{Cl}^{-}$ concentration than systemic blood to peritubular capillaries and serves to maximize the magnitude of the transepithelial $\mathrm{Cl}^{-}$concentration gradient (lumen to blood) in late proximal segments. If tubular and capillary flows were cocurrent, reabsorbate with a $\mathrm{Cl}^{-}$concentration higher than in efferent blood will be added 

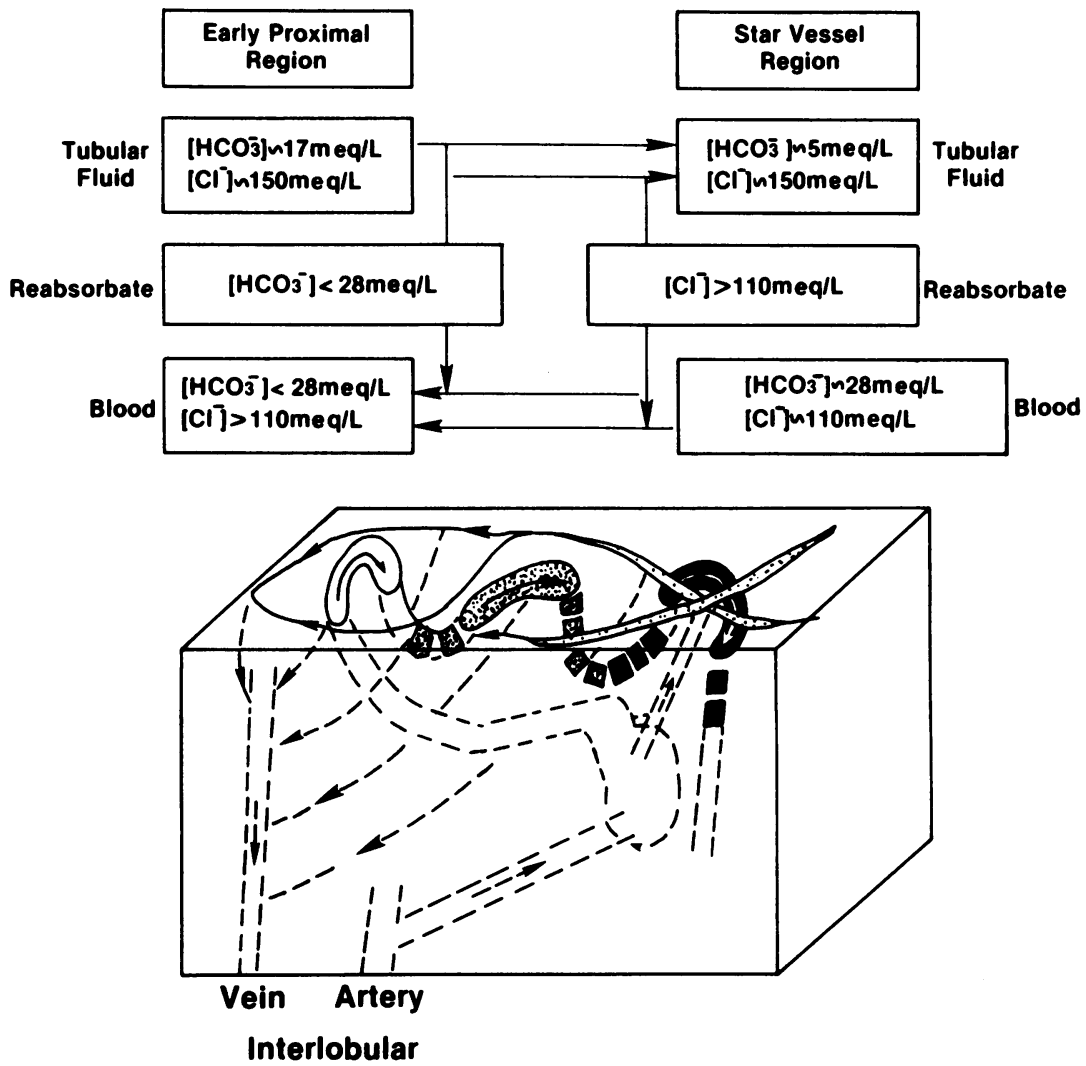

Figure 3. Diagram of outer cortex depicting superficial and deep countercurrent systems. In the superficial system $\mathrm{Cl}^{-}$reabsorption in mid- and late proximal segments is facilitated by the favorable $\mathrm{Cl}^{-}$gradient across the tubular wall. Preferential reabsorption of $\mathrm{Cl}^{-}$over $\mathrm{HCO}_{3}^{-}$in mid- and late proximal convolutions (2) will be expected to increase $\mathrm{Cl}^{-}$concentration and decrease that of $\mathrm{HCO}_{3}^{-}$in peritubular capillaries. ${ }^{2}$ The lowering of $\mathrm{HCO}_{3}^{-}$in capillary blood should minimize the impact of addition of $\mathrm{HCO}_{3}^{-}$-rich reabsorbate in the early proximal region. Delivery of surface blood relatively rich in $\mathrm{Cl}^{-}$and poor in $\mathrm{HCO}_{3}^{-}$to the deep countercurrent system should facilitate $\mathrm{HCO}_{3}^{-}$ reabsorption in the very early proximal tubule. $\mathrm{L}$, liter.

to peritubular capillaries progressively reducing the transepithelial $\mathrm{Cl}^{-}$concentration gradient, thus retarding $\mathrm{Cl}^{-}$reabsorption in downstream segments. The superficial countercurrent flow system may also influence $\mathrm{HCO}_{3}^{-}$transport in the superficial proximal tubule. In this case, however, the system may be poised to promote $\mathrm{HCO}_{3}^{-}$reabsorption in early convolutions. Because reabsorbate from mid- and late proximal convolutions has a relatively low $\mathrm{HCO}_{3}^{-}$concentration its addition to peritubular capillaries should reduce $\mathrm{HCO}_{3}^{-}$concentration in capillary blood. Delivery via the countercurrent system of blood with a relatively low $\mathrm{HCO}_{3}^{-}$concentration to the early proximal tubule should ameliorate the rise in capillary blood $\mathrm{HCO}_{3}^{-}$concentration consequent to the higher rate of $\mathrm{HCO}_{3}^{-}$reabsorption in this segment. In this fashion $\mathrm{HCO}_{3}^{-}$concentration in early proximal capillaries could be kept at a level lower than in late proximal capillaries. Keeping of $\mathrm{HCO}_{3}^{-}$concentration in early proximal capillaries at reduced levels may be necessary to maintain the higher $\mathrm{H}^{+}$secretory rate they are capable of as suggested by our $\mathrm{pH}_{\mathrm{i}}$ studies.

The nephron organizational pattern found on the renal surface may be also of relevance concerning the declining axial $\mathrm{PCO}_{2}$ gradient described by Maddox et al. (34) in the lumen and peritubular capillaries along the proximal tubule. Clustering of proximal convolutions into discrete areas will tend to build up local $\mathrm{PCO}_{2}$ concentration differences. In addition, the countercurrent pattern of tubular fluid and capillary blood flows would also help to maintain luminal $\mathrm{PCO}_{2}$ differences between early and late proximal convolutions by allowing for a more efficient loss of luminal $\mathrm{CO}_{2}$ into peritubular capillaries as tubular fluid flows along the proximal tubule. These considerations make it likely that the concentric pattern of $\mathrm{pH}_{\mathrm{i}}$ differences on the renal surface may be mirrored by a similar pattern of luminal and capillary $\mathrm{PCO}_{2}$ differences which may involve the intracellular compartment as well.

In summary, these results demonstrate that $\mathrm{pH}_{\mathrm{i}}$ declines axially along the superficial proximal convoluted tubule. Because surface convolutions emerge in a highly organized fashion, the axial $\mathrm{pH}_{\mathrm{i}}$ gradient is expressed as nearly concentric areas with the clustering next to the star vessel having the most acidic values of cell $\mathrm{pH}$. This axial heterogeneity is due in part to the declining profile of luminal $\mathrm{pH}$ or $\mathrm{HCO}_{3}^{-}$concentration and in part to differences in the mechanisms of $\mathrm{pH}_{\mathrm{i}}$ regulation in the two segments. We propose that this difference represents an enhanced rate of active $\mathrm{H}^{+}$extrusion across the luminal membrane.

\section{Acknowledgments}

The authors are indebted to Pamela Geller and Antionette Leggett for their help in preparing the manuscript.

These studies were supported by a Merit Review grant of the Veterans Administration.

2. $\mathrm{HCO}_{3}^{-}$and $\mathrm{Cl}^{-}$concentrations in star vessel plasma have been reported (7) to be 28 and $102 \mathrm{meq} / \mathrm{liter}$, respectively (compared with systemic values $\Delta \mathrm{HCO}_{3}^{-}=+6 \mathrm{meq} / \mathrm{liter}$ and $\Delta \mathrm{Cl}^{-}=-8 \mathrm{meq} / \mathrm{liter}$ ). Using the values of Liu and Cogan et al. (2) for segmental $\mathrm{HCO}_{3}^{-}, \mathrm{Cl}^{-}$and fluid reabsorption in the last $3 \mathrm{~mm}$ of the proximal tubule (length of accessible proximal tubule in Sprague-Dawley studies in our laboratory), reabsorbate $\mathrm{HCO}_{3}^{-}$and $\mathrm{Cl}^{-}$concentration in the $1 \mathrm{st} \mathrm{mm}$ of the superficial proximal tubule can be calculated to be 28 and $165 \mathrm{meq} / \mathrm{liter}$, respectively, and those in mid and late segments (last $2 \mathrm{~mm}$ ) 22 and $152 \mathrm{meq} / \mathrm{liter}$. 


\section{References}

1. Ullrich, K. J., G. Rumrich, and K. Baumann. 1975. Renal proximal tubular buffer-(glycodiazine) transport. Inhomogeneity of local transport rate, dependence on sodium, effect of inhibitors and chronic adaptation. Pfluegers Arch. Eur. J. Physiol. 357:149-163.

2. Liu, F.-Y., and M. G. Cogan. 1984. Axial heterogeneity in the rat proximal convoluted tubule. I. Bicarbonate, chloride and water transport. Am. J. Physiol. 247 (Renal Fluid Electrolyte Physiol. 16):F816-F821.

3. Cogan, M. G., and R. J. Alpern. 1984. Regulation of proximal bicarbonate reabsorption. Am. J. Physiol. 247 (Renal Fluid Electrolyte Physiol. 16):F387-F395.

4. Maddox, D. A., and F. J. Gennari. 1985. Load dependence of $\mathrm{HCO}_{3}$ and $\mathrm{H}_{2} \mathrm{O}$ reabsorption in th early proximal tubule of the MunichWistar rat. Am. J. Physiol. 248 (Renal Fluid Electrolyte Physiol. 17): F113-F121.

5. Malnic, G., and M. De Mello-Aires. 1971. Kinetic study of bicarbonate reabsorption in proximal tubule of the rat. Am. J. Physiol. 220: 1759-1767.

6. Alpern, R. J., M. G. Cogan, and F. C. Rector, Jr. 1982. Effect of luminal bicarbonate concentration on proximal acidification in the rat. Am. J. Physiol. 243 (Renal Fluid Electrolyte Physiol. 12):F53-F59.

7. Alpern, R. J., M. G. Cogan, and F. C. Rector, Jr. 1983. Flow dependence of proximal tubular bicarbonate reabsorption. Am. J. Physiol. 245 (Renal Fluid Electrolyte Physiol. 14):F478-F484.

8. Pastoriza-Munoz, E., R. E. Colindres, W. E. Lassiter, and C. Lechene. 1978. Effect of parathyroid hormone on phosphate reabsorption in rat distal convolution. Am. J. Physiol. 235:F321-F330.

9. DuBose, T. D., L. R. Pucacco, M. S. Lucci, and N. W. Carter. 1979. Micropuncture determination of $\mathrm{pH}, \mathrm{pCO}_{2}$ and total $\mathrm{CO}_{2}$ concentration in accessible structures of the rat renal cortex. J. Clin. Invest. 64:467-482.

10. Alpern, R. J. 1985. Mechanism of basolateral membrane $\mathrm{H}^{+} /$ $\mathrm{OH}^{-} / \mathrm{HCO}_{3}^{-}$transport in the rat proximal convoluted tubule: a sodiumcoupled electrogenic process. J. Gen. Physiol. 86:613-636.

11. Boron, W. F., and H. Sackin. 1983. Measurement of intracellular ionic composition and activities in renal tubules. Annu. Rev. Physiol. 45:483-496.

12. Graber, M. L., T. E. Dixon, D. Coachman, K. Herring, A. Ruenes, T. Gardner, and E. Pastoriza-Munoz. 1985. Fluorescence identifies an alkaline cell in turtle urinary bladder. Am. J. Physiol. 250 (Renal Fluid Electrolyte Physiol. 19):F159-F168.

13. Graber, M. L., D. C. DiLillo, B. L. Friedman, and E. PastorizaMunoz. 1986. Characteristics of fluoroprobes for measuring intracellular pH. Anal. Biochem. 156:202-212.

14. Renault, G., E. Raynal, M. Sinet, M. Muffat-Joly, J.-P. Berthier, J. Cornillault, B. Godard, and J.-J. Pocidalo. 1984. In situ double-beam NADH laser fluorimetry: choice of a reference wavelength. Am. J. Physiol. 246 (Heart Circ. Physiol. 15):H491-H499.

15. Anderson, R. E., J. D. Michenfekder, and T. M. Sundt, Jr. 1980. Brain intracellular $\mathrm{pH}$, blood flow and blood brain barrier differences with barbiturate and halothane anesthesia in the cat. Anesthesiology. 52: 202-206.

16. Fink, D. W., and W. R. Koehler. 1970. pH effects on fluorescence of umbelliferone. Anal. Chem. 42:990-993.

17. Gerson, D. F. 1982. Determination of intracellular pH changes in lymphocytes with 4-methylumbelliferone by flow microfluorometry. In Intracellular pH: Its Measurement, Regulation and Utilization in Cellular Functions. Alan R. Liss, Inc., New York. 124-133.

18. Thomas, J. A., R. N. Buchsmbaum, A. Zimniak, and E. Racker. 1979. Intracellular pH measurements in Ehrlich ascites tumor cells utilizing spectroscopic probes generated in situ. Biochemistry. 18:22102218.

19. Schwartz, G. J., and Q. Al-Awqati. 1984. Use of fluorescent dyés to measure cell $\mathrm{pH}$ in identified acid-secreting cells of renal tubules. Kidney Int. 25:282. (Abstr.)

20. Piwnica-Worms, D., and M. Lieberman. 1983. Microfluorometric monitoring of $\mathrm{pH}_{\mathrm{i}}$ in cultured heart cells: $\mathrm{Na}^{+}-\mathrm{H}^{+}$exchange. $A m$. J. Physiol. (Cell Physiol. 13) 244:C422-C428.

21. Yoshitomi, K., and E. Fromter. 1984. Cell pH of rat renal proximal tubule in vivo and the conductive nature of peritubular $\mathrm{HCO}_{3}^{-}$ $\left(\mathrm{OH}^{-}\right)$exit. Pfluegers Arch. Eur. J. Physiol. 402:300-305.

22. Alpern, R. J., and M. Chambers. 1986. Cell pH in the rat proximal convoluted tubule: regulation by luminal and peritubular $\mathrm{pH}$ and sodium concentration. J. Clin. Invest. 78:502-510.

23. Schwartz, J. H., and M. Tripolone. 1983. Intracellular $\mathrm{pH}$ of granular and mitochondrial-rich cells of turtle bladder. Kidney Int. 23: 239. (Abstr.)

24. Kinsella, J. L., and P. S. Aronson. 1980. Properties of the $\mathrm{Na}^{+}$$\mathrm{H}^{+}$exchanger in renal microvillus membrane vesicles. Am. J. Physiol. 238 (Renal Fluid Electrolyte Physiol. 7):F461-F469.

25. Schwartz, G. J. 1981. $\mathrm{Na}^{+}$-dependent $\mathrm{H}^{+}$efflux from proximal tubule: evidence for reversible $\mathrm{Na}^{+} \mathrm{H}^{+}$exchange. Am. J. Physiol. 241 (Renal Fluid Electrolyte Physiol. 10):F380-F385.

26. Aronson, P. S., J. Nee, and M. A. Suhm. 1982. Modifier role of internal $\mathrm{H}^{+}$in activating the $\mathrm{Na}^{+}-\mathrm{H}^{+}$in renal microvillus membrane vesicles. Nature (Lond.). 299:161-163.

27. Bank, N., H. S. Aynedjian, and B. F. Mutz. 1985. Evidence for a DCCD-sensitive component of proximal bicarbonate reabsorption. Am. J. Physiol. 249 (Renal Fluid Electrolyte Physiol. 18):F636-F644.

28. Warnock, D. G., and V. J. Lee. 1981. Chloride uptake by brush border membrane vesicles isolated from rabbit renal cortex: coupling to proton gradients and $\mathrm{K}^{+}$diffusion potentials. J. Clin. Invest. 67:103115.

29. Shiuan, D., and S. W. Weinstein. 1984. Evidence for electroneutral chloride transport in rabbit renal cortical brush border membrane vesicles. Am. J. Physiol. 247 (Renal Fluid Electrolyte Physiol. 16):F837-F847.

30. Gertz, K. H., J. A. Mangos, G. Braun, and H. D. Pagel. 1966. Pressure in the glomerular capillaries of the rat kidney and its relation to arterial blood pressure. Pfluegers Arch. Eur. J. Physiol. 288:369-374.

31. Steinhausen, M., G. M. Eisenbach, and R. Galasky. 1970. A countercurrent system of the surface of the renal cortex of rats. Pfluegers Arch. Eur. J. Physiol. 318:244-258.

32. Weinstein, S. W., and J. Szyjewicz. 1976. Early postglomerular plasma concentrations of chloride, sodium and inulin in the rat kidney. Am. J. Physiol. 231:822-831.

33. Weinstein, S. W., and J. Szyjewicz. 1978. Superficial nephron tubular-vascular relationships in the rat kidney. Am. J. Physiol. 234 (Renal Fluid Electrolyte Physiol. 3):F207-F214.

34. Maddox, D. A., L. J. Atherson, W. M. Deen, and F. J. Gennari. 1984. Proximal $\mathrm{HCO}_{3}^{-}$reabsorption and the determinants of tubular and capillary $\mathrm{PCO}_{2}$ in the rat. Am. J. Physiol. 247 (Renal Fluid Electrolyte Physiol. 16):F73-F81. 